\title{
LIST OF FIGURES, TABLES, AND MAPS
}

\section{FIGURES}

4.1 Swidden pattern of Setaria italica of Taiwan Central Mountain tribes

5.1 Comparison of artifacts from the Hsü-Hai area

5.2 Comparison of artifacts from north and south of the Yangtze

5.3 Ceramic sequence for the Ch'ing-lien-kang culture south of the Yangtze

5.4 Ceramic sequence for the Ch'ing-lien-kang culture north of the Yangtze

5.5 Stone tools, early Ch'ing-lien-kang, from Yü-tun-ts'un, Kiangsu

7.1 Po. Ta-ho-ts'un, Cheng-chou, Honan

7.2 Unpainted wares from Ta-ho-ts'un, Cheng-chou, Honan

7.3 P'en. Miao-ti-kou, Shan-hsien, Honan

7.4 Procedure for inscribing a Miao-ti-kou spiral design

7.5 Degeneration of the Miao-ti-kou spiral design

7.6 P'en. Miao-ti-kou, Shan-hsien, Honan

7.7 Vessels from Ta-tun-tzu, P'i-hsien, Kiangsu

7.8 Po. P'i-hsien, Kiangsu

7.9 Kuei. Hsi-hsia-hou, Ch'ü-fu-hsien, Shantung 197

7.10 Tou. Hsi-hsia-hou, Ch'ü-fu-hsien, Shantung 198

7.11 Pei. Hsi-hsia-hou (upper stratum), Ch'ü-fu-hsien, Shantung

7.12 Vessels from Tung-hai-yü, Jih-chao-hsien, Shantung 
7.13 Vessels from Wei-fang-hsien, Shantung 201

7.14 Ceramic vessels based on sheet metal prototypes $; 08$

9.1 Diagrammatic rendering of radiocarbon-dated sites 239

9.2 Construction of a leaf hinge by smithy methods 255

9.3 Model and mold assembly for the casting of hinges 257

9.4 Transition from the articulated terminal grip to the hinge 259

9.5 Rubbings of the Ts'ai-hou-mu hinge 260

9.6 Structure of the ho-yeh (or huo-chia) strap terminal 261

9.7 An early Han plate hinge, apparently with axle-pin 264

9.8 An unusual development in hinge design 265

9.9 Han period hinge with iron pin from Sha-hu-ch'iao, Ch'ang-sha 268

10.1 Schematic classification of materials selection and processing 283

11.1 Discriminant analysis of male crania $\quad 307$

11:2 Plot of discriminant functions 3 and $4 \quad 308$

11.3 Discriminant analysis on cranial series selected with reference to alleged "types" perceived in the An-yang crania

11.4 Same analysis as figure 11.3, but plotting mean positions of the same series and individual specimens on functions 3 and 4

12.1 Incised marks on pottery from Pan-p'o 324

12.2 Graphs inscribed on pottery from Chiang-chai 326

12.3 Pottery inscriptions from Ta-wen-k'ou sites 327

12.4 Painted symbol from Pao-t'ou-ts'un 328

12.5 Inscriptions on potsherds from Ch'eng-tzu-yai 331

12.6 Marks incised on pots from Sung-tse-ts'un $\quad 332$

12.7 Marks incised on pots of Liang-chu culture date 333

12.8 Marks incised on pots from Ma-ch'iao 334

12.9 Incised pottery graphs, Pan-shan/Ma-ch'ang cultures 334

12.10 Graphs painted on Ma-ch'ang style pottery 335 
12.11 Pottery inscriptions from Erh-li-t'ou sites 336

12.12 Painted graph from Miao-wan 337

12.13 Marks incised on potsherds from the Early Shang level, Hsia-ch'i-yüan

12.14 Wu-ch'eng inscriptions dated to Period I 338

12.15 Wu-ch'eng inscriptions dated to Periods II and III 341

12.16 Inscriptions on potsherds from Erh-ti-kang 342

12.17 Inseriptions on potsherds from Nan-kuan-wai 344

12.18 Inscriptions on potsherds from T'ai-hsi-ts'un 345

12.19 Pottery graphs from the Middle Shang level, Hsia-ch'iyüan

12.20 Signs from Hsin-tien pottery urns 346

12.21 Inscriptions on potsherds from Ma-ch'iao 348

12.22 Inscriptions on potsherds from Hsiao-t'un 351

12.23 Late Shang inscribed potsherds from Mei-yüan-chuang and Ta-ssu-k'ung-ts'un

12.24 Inscriptions on potsherds from the Late Shang level, Hsia-ch'i-yüan

12.25 Inscriptions on unprovenanced ceramics in public and private collections

12.26 Inscribed potsherds from Feng-pi-t'ou 355

12.27 Pottery inscriptions from Hoi-fung and Hong Kong 357

12.28 The concurrent appearance of both "primitive" and "advanced" graphs in pottery inscriptions

12.29 Unusual combinations of numerals $\quad 379$

15.1 "Tribe" as a neatly bounded system 472

15.2 "Tribe" as a test core 473

TABLES

4.1 Setaria italica varieties from Tung-pu, Nan-t'ou-hsien

4.2 Comparison of the foxtail millet swidden cultivation cycle

5.1 Radiocarbon dates' for Ch'ing-lien-kang and other early sites in the lower and middle Yangtze area 
9.1 Radiocarbon-dated sites of Yang-shao, Lung-shan, and Lungshanoid types

10.1 Finds of gold foil in Shang China 290

11.1 Mean measurements of Chinese cranial series 303

11.2 Standard deviations of Hainan and An-yang series compared to generalized world mean standard deviations 306

11.3 "Hits-and-misses" table of classification by discriminants 311

12.1 Pottery inscriptions from Wu-ch'eng 340

12.2 Chronological list of sites with inscribed pottery 362

12.3 Pottery graphs from Wu-ch'eng compared with graphs from oracle bones and bronze inscriptions

12.4 Identical and nearly identical pottery graphs from various sites

16.1 Development model of Sandai civilizations 513

17.1 Shang places with a state score of 150 or more 541

\section{MAPS}

Major archaeological sites in this volume

xxvi

3.1 Geographic distribution of the cereals and of soybeans during the Chou

3.2 Geographic distribution of rice 71

5.1 Land and sea level changes in the Shanghai area 133

5.2 Sites in the vicinity of Huai-yin-hsien, Kiangsu 135

5.3 Neolithic sites in Kiangsu and northern Chekiang 139

7.1 Lung-shan sites in eastern China 188

7.2 Distribution of ceramic copies of wrought metal vessels, ca. 2000 B.C.

8.1 Neolithic migrations in China between the fifth and the third millennia B.C.

12.1 Sites with inscribed pottery 381

17.1 State scores of the Late Shang state 538

17.2 State scores of major allies and enemies in Late Shang 539

17.3 Major regions of the Late Shang state 544 